\title{
A PERSPECTIVA DA PENSATIVA TRACCA DE LIVRO QUANTO À PESQUISA LITERÁRIA E LINGUÍSTICA
}

\section{THE THINKING BOOKWORM'S VIEW OF LITERARY AND LINGUISTIC RESEARCH}

\author{
Suman Gupta ${ }^{1}$
}

Traduzido por

Matheus Barbosa Morais de Brito ${ }^{2}$

RESUMO: Trata-se da tradução da conferência de abertura do XXXI Encontro Nacional da ANPOLL, pronunciada pelo Professor Doutor Suman Gupta (Open University) em 29 de julho de 2016 no Centro de Conferências da Universidade Estadual de Campinas. Gupta discute a herança filológica como horizonte das práticas acadêmicas correntes nos estudos literários, suas transformações e possibilidades de renovação.

\begin{abstract}
This is a translation of the opening lecture of the $31^{\text {st }}$ National ANPOLL Meeting by Dr. Suman Gupta (Open University) on July 29, 2016, which was held at the Universidade Estadual de Campinas Conference Center. Gupta discusses philological heritage as a horizon for current academic practice in literary studies, its transformation and possibilities for renewal.
\end{abstract}

\footnotetext{
${ }^{1}$ Professor na The Open University, Reino Unido. Milton Keynes, Reino Unido. E-mail: suman.gupta@open.ac.uk

${ }^{2}$ Doutor em Materialidades da Literatura (2016) pela Universidade de Coimbra, Portugal. Graduado em Português (2011) pela mesma universidade. Coimbra, Portugal. E-mail: theosdebrito@gmail.com
} 
"Pesquisa de ponta na área de letras e linguística", o ímpeto perfurante, a linha de frente a ser impulsionada: isso sugere olhar adiante. Olhar adiante, no entanto, depende de saber onde estamos e de onde viemos. Minhas próprias tentativas de olhar adiante parecem envolver, na maioria das vezes, um olhar para trás na disciplina - e no disciplinamento - da investigação literária e linguística, em particular para a esfera sociocultural com a qual estou levemente familiarizado.

Isso inclui ler traduções. Aconteceu-me de estar lendo recentemente uma vigorosa tradução de Dom Casmurro, de Machado de Assis, e surgiu esta excelente descrição do breve lapso do narrador epônimo sobre esta pesquisa, provocada por uma citação bíblica e uma alusão à cultura helênica tenuamente vinculada (ela mesma de uma origem tênue, tentadora): 
Ele fere e cura!" Quando, mais tarde, vim a saber que a lança de Aquiles também curou uma ferida que fez, tive tais ou quais veleidades de escrever uma dissertação a este propósito. Cheguei a pegar em livros velhos, livros mortos, livros enterrados, a abrilos, a compará-los, catando o texto e o sentido, para achar a origem comum do oráculo pagão e do pensamento israelita. Catei os próprios vermes dos livros, para que me dissessem o que havia nos textos roídos por eles.

"Meu senhor", respondeu-me um longo verme gordo, "nós não sabemos absolutamente nada dos textos que roemos, nem escolhermos o que roemos, nem amamos ou detestamos o que roemos; nós roemos."

Não lhe arranquei mais nada. Os outros todos, como se houvessem passado palavra, repetiam a mesma cantilena. Talvez esse discreto silêncio sobre os textos roídos fosse ainda um modo de roer o roído. (Cap. XVII, "Os Vermes")

Essa passagem pareceu-me uma metáfora esplêndida para auxiliar no que quero dizer aqui.

A metáfora põe em bom foco um conjunto de práticas de pesquisa que descrevem uma formação de conhecimento, a qual podemos considerar textual e linguística: fazer investigação de arquivo, leitura cerrada e comparação textual (corroboração formalista de vários tipos), para chegar, em última instância, a uma "origem comum" (dos textos) numa compreensão unitária de psiquês e culturas específicas (do paganismo e do pensamento hebraico). Essas práticas, por si mesmas, ainda são variadamente subscritas, mas, do nosso ponto de vista, juntas elas sugerem certa formação anacrônica de conhecimento: na verdade, elas oferecem uma sucinta e precisa descrição do que costumava ser considerado filologia. Filologia sugere, abriga em si, um grupo de empresas acadêmicas relacionadas - como estudos clássicos, hermenêutica religiosa, filologia comparativa, linguística histórica, bibliografia analítica e edótica - mas também permanece maravilhosamente vaga e expansiva, um significante para a própria atividade acadêmica. A Filologia foi a estrutura dominante da profissão do estudo textual e linguístico na época em que Machado escrevia.

$\mathrm{O}$ instrumento usado para trazer à tona essa formação, em vez de simplesmente segui-la como óbvia - para, por assim dizer, lançá-la adiante - é de interesse particular hoje, na nossa vanguarda, embora deva ter parecido frívolo para os primeiros leitores de Machado. A traça de livros pode ser indiferente ao conteúdo do texto, mas não é indiferente ao material do livro: ela tira dele sua subsistência. Metaforicamente, é claro, assim também a indústria de livros, as editoras, vendedores - toda uma matriz circulatória para disseminar (roer) o texto em formas materiais. É claro, nenhum deles é completamente indiferente ao texto, mas a materialidade dos livros e sua circulação não estão no interior do texto embora textos aparentemente carreguem compreensões várias da textualidade. $\mathrm{O}$ predominante interesse acadêmico em como isso acontece explica muito sobre o porquê dos estudos filológicos descritos por Machado parecerem um tanto anacrônicos hoje, embora nós ainda subscrevamos às práticas por eles 
promovidas. A linha que vai da filologia aos estudos literários e linguísticos do presente envolve, da parte dos pesquisadores, uma atitude como a da traça em relação aos livros, mas sem que aqueles se metamorfoseiem em traças, sem que se tornem indiferentes ao conteúdo dos textos (embora alguns autores, editoras e críticos produzam quantidades vultosas de polpa de fácil digestão). O que surgiu foi um tipo de perspectiva da traça pensante sobre consumir materialmente livros que contêm textos. Considerando que eu tenho um certo carinho por esse confuso prefixo, penso nessa condição como a "visão pós-traça" - eu brinquei com "prototraça", mas "pós-traça" soa mais denso.

Permitam-me um pequeno desvio. Nos últimos anos eu estive lendo histórias da formação dos Estudos Anglófonos como uma disciplina acadêmica o estudo da literatura e da linguagem na pedagogia e na investigação institucional, dos Estudos Anglófonos no Reino Unido, Estados Unidos, Índia, Europa Continental, e de certa forma por toda parte. Dada a dominação política do idioma inglês, esse é um conjunto bem disperso de histórias. Estados Unidos e Inglaterra têm histórias bastante antigas dos Estudos Anglófonos, não realmente muito mais velhas que as da Alemanha ou da Índia - mas vou falar um pouco sobre os casos britânico e americano.

O projeto de historicizar os Estudos Anglófonos nos Estados Unidos e no Reino Unido parece derivar de impulsos um tanto diferentes, diferentes rationales historiográficas. As histórias britânicas (a começar pelo Newbolt Report de 1921, e então, num modo acadêmico: PALMER, 1965; BALDICK, 1983; DOYLE, 1989; DIXON, 1991; CRAWFORD, 1992; COURT, 1992; MILLER, 1997; MOMMA, 2013) são em grande medida histórias sociais - esse tipo de história reflete sobre as forças sociais e políticas que atuam sobre a disciplina: através da circulação de ideias socialmente relevantes, a intervenção de interesses particulares, imperativos político-econômicos, etc. Em geral, as histórias americanas da disciplina (OHMANN, 1976; GRAFF, 1987; SCHOLES, 1998; MILLER, 2010) explicitamente trouxeram à tona o papel mediador da instituição e da profissão acadêmica, enquanto operando entre o conteúdo intelectual da disciplina e forças sociais mais amplas.

Como base comum, as histórias disciplinares de ambos os contextos respondiam a algo que parecia tornar-se institucionalmente premente e então incutida dos anos 1970 a 1990, a chamada Teoria (com T maiúsculo) - assim, ad maiores referências de tal empreitada histórica são daquele período. Eu não tentarei sumarizar o que é Teoria; vocês provavelmente estão aptos a fazê-lo de maneira mais adequada do que eu. De qualquer modo, a empreitada historicizante foi em geral um aflito acerto de contas com o advento da Teoria nas humanidades. Além disso, o que também une ambos os contextos de historicização dos Estudos Anglófonos é que eles, mais ou menos unanimemente, 
tomam a atual formação disciplinar como um afastamento de uma antiga estrutura de estudos literários e linguísticos - compreendido quer como o passado estudo da filologia quer como do estudo da retórica. Os Estudos Anglófonos de então, afirma-se consistentemente, derivam de algo chamado de filologia ou da retórica, mas não mais se baseiam nessas disciplinas; filologia/retórica já deu, estão quase esquecidas. É verdade que esses historiadores compreendem a filologia de maneira bem distinta: alguns (sobretudo os alemães) pensam-na essencialmente como linguística comparativa, a qual, através de Wilhelm Humboldt e suas reformas educacionais na Prússia, deu base à profissionalização da moderna universidade; outros enfatizam, com base nas mesmas fontes, sua cumplicidade às ideologias de raça e nação; alguns pensam-na como encarregada de tratar de mudanças verbais e consonantais e das origens das palavras em textos; outros ainda, como algo que diz respeito à edição de manuscritos Clássicos, Bíblicos, Anglo-Saxões; e quase todos acordam que ela envolve uma espécie combinada de exame linguístico através de textos literários e vice-versa. Alguns preferem fazer uma distinção marcada entre filologia e retórica como distintos horizontes de afastamento da moderna disciplina - embora seja difícil estabelecer a diferença se os termos forem examinados bem de perto. Parece provável que, antes do século XIX - e ocasionalmente durante e logo após -, a base conceitual da retórica poderia ser encontrada na filologia. A retórica poderia ser pensada como uma área de aplicação prática que complementava ou era auxiliar ao estudo filológico, às vezes até mesmo considerada como seu subconjunto. A situação poderia ser pensada como análoga à relação entre linguística aplicada e linguística teórica agora: o suporte conceitual desta é articulada naquela, enquanto as intervenções mundanas daquela são ativadas nesta. E, claro, a vaguidão do termo "filologia" em inglês tem dimensões particulares: em inglês, é comum de se compreender "filologia", de um modo bem restrito, como linguística pré-saussurriana, ou como "ciência da língua" como investigada antes da formulação da linguística geral. Porém, na Europa Continental, como Otto Jespersen memoravelmente observou, "filologia" é empregue num sentido que "normalmente é traduzido em inglês pela vaga expressão 'atividade acadêmica', significando assim o estudo de uma cultura específica a uma nação" (1922, p. 64). Este último sentido, de fato, é pertinente para as nossas observações - e a maior parte das histórias mencionadas toma esse sentido como o mais significativo.

A despeito da vaguidão e da porosidade, parece consensualmente aceite que a filologia foi a armação sobre a qual a investigação linguística e literária costumava ser conduzida, o que já não é o caso.

Embora os afastamentos da filologia tenham sido examinados em histórias disciplinares lidando com ansiedade quanto à Teoria, nos círculos institucionais da Teoria dos anos 1970 a 1990 quase não se menciona a filologia. Os debates da Teoria daquela época interrogaram e analisaram todo tipo de silêncio e premissa ideologicamente carregados que fossem relevantes tanto para o estudo literário como para a linguística (nos discursos imperialista, capitalista, nacionalista, essencialista, humanista, historicista, etc.). Esses debates foram memoráveis e inquestionavelmente mudaram os rumos da investigação e do ensino. Os 
numerosos manuais de Teoria que então se produziram para dar apoio aos programas de linguagem e de literatura em ampla medida negligenciaram a filologia, e com efeito este é ainda o caso. Dentre os primeiros e mais continuamente populares, o Critical Practice (1980) de Catherine Belsey não menciona o termo, e o Literary Theory (1983) de Terry Eagleton chegou a fazê-lo uma vez, sem dar-lhe mais explicação. A filologia era mencionada apenas de passagem ou simplesmente não aparecia nos manuais, guias e livros de referência cada vez mais simplificados de Teoria. Um dos poucos eventos sobre filologia nos anos 1980, envolvendo partidários da Teoria nos Estados Unidos, foi uma conferência intitulada "What is Philology?" em Harvard, a 19 de março de 1988. A questão do título tinha um ar de perplexidade. O volume subsequente, On Philology (1990), organizado por Jan Ziolkowski, mostra como os colaboradores com frequência abordaram o tópico de modo apologético ou evasivo. A introdução cativantemente franca de Ziolkowski lembrava a dificuldade que ele teve em convidar acadêmicos de relevância para falar, e como eles com frequência se persuadiram a voltar a um breve texto de Paul de Man, "The Return to Philology" (1982). Um retorno, claro, sugere que um afastamento já se havia dado.

Essa referência ao ensaio de De Man indica, no entanto, o fato de que embora a filologia já não causasse grande impressão na institucionalização da Teoria, e parecesse uma coisa já passada, ela continuava a fermentar - persistia como substrato do estudo linguístico e literário. E por isso ocasionalmente se ouve (com efeito com crescente frequência) apelos por seu retorno.

Por trás de De Man está a duradoura influência da tentativa de Leo Spitzer e, especialmente, de Erich Auerbach de articular uma prática cosmopolita da filologia. Variadamente, Seth Lerer e, com mais influência, Edward Said continuaram voltando a essa explicação cosmopolita. A influência deste último era ainda mais profunda, já que sua obra anterior sobre o Orientalismo parecia ir contra o grão de certos preconceitos filológicos; seu próprio "Return to Philology" (2002) foi então recebido com considerável interesse. Em Janeiro de 1990 apareceu um volume especial da revista Speculum (a mais venerável em relação ao estudo da Idade Média nos Estados Unidos), organizado por Stephen Nichols sob o título de "New Philology". As contribuições aí encontradas tratavam especialmente de defender o exercício da filologia - e concomitante dos textos medievais - contra a investida da Teoria. Depois disso, Nichols desenvolveu uma prática um pouco diferente, de "filologia material" (NICHOLS, 1997). The Powers of Philology (2002), de Hans Ulrich Gumbrecht, reiterou a centralidade da filologia em relação à "curadoria do texto histórico". Reconceitualizações e revitalizações da filologia apareceram aqui e ali desde virada do milênio, com um otimismo cada vez maior (cite-se uma pequena parte: LERER, 2002b; WARREN, 2003; POLLOCK, 2009; GURD (Org.), 2010; BAJOHR et al. (Org.), 2014). De modo pouco surpreendente, as reflexões de Geoffrey Harpham sobre a condição das Humanidades, e breve revista das associações nacionalista e racista da história da filologia, concluíram que a filologia: "não pode ser considerada uma fascinação temporária ou humor 
recorrente, mas deve, ao contrário, ser vista como um aspecto característico e permanente do estudo humanístico, uma profunda corda vibrando sob os estudos literários em particular" (2011, p. 76). Ele recomendou uma "reaparição" conscienciosa da filologia e o cuidadoso discernimento entre a boa e a má filologia. Já a história da filologia de Joseph Turner (2014) tentou recuperar a base na filologia não apenas nos estudos de linguagem e literatura como também na moderna historiografia, na etnologia e nos estudos da religião.

Todos esses são movimentos interessantes e algo contraditórios: a filologia parece algo que já deu, que passou, nas recentes histórias das disciplinas de linguística e literatura; a filologia é tratada com prudência e não muito discutida na Teoria institucional; a filologia continua a ser venerada nalguns círculos e há ocasionais apelos por seu retorno. Quando algo é dado como morto por uns, ignorado por outros e defendido por poucos, parece estar implicado numa problemática - numa complexidade - de nosso tempo, o presente. Parece razoável suspeitar que a filologia tem algum impacto na atual investigação linguística e literária, e, no entanto, de um jeito que causa desconforto. E essa parece ser uma excelente razão para tratar dela - para ir a fundo. O que quer que lance luz sobre o presente bem pode lançar alguma sobre o futuro hoje projetado.

Permitam-me voltar à metáfora de Machado, ou melhor, à minha pequena modificação dessa metáfora: a prática filológica descrita e a visão "pós-traça" contra a qual ela se orienta como se já estivesse vacinada.

Pretendo sugerir o seguinte. A herança filológica da investigação literária e linguística implica que várias práticas associadas àquela estruturação do conhecimento continuam incorporadas na pesquisa. Já não se lhes subscreve enquanto necessariamente correlativas ao conhecimento filológico, mas simplesmente por uma questão de hábito, com base numa convicção muito firme. Isso diz respeito a um foco intenso no conteúdo e na composição de textos (um arranjo abstrato de signos).

De todo modo, a própria estrutura filológica do conhecimento parece anacrônica porque os pressupostos associados à prática de focar o texto de modo intensivo foram debilitados, ou ao menos complexificados pela atenção às condições materiais que cercam textos: as formas materiais dos textos (livros, hipertextos, adaptações audiovisuais), as condições materiais de autoria e leitura, e as economias da produção e disseminação literária e linguística. Essa é a visão pós-traça da área.

Desse modo, há práticas de pesquisa filologicamente inspiradas com as quais estamos acostumados, nas quais acreditamos, aceitando como usuais; ao mesmo tempo, também subscrevemos à visão pós-traça, que nos torna conscientes quanto às limitações daquelas práticas e põe em dúvida seu movimento. Uma vez que estejamos hoje presos entre a herança filológica e a 
complicação "pós-traça", temos uma difícil relação com a filologia: sabemos que ela passou, não queremos falar sobre ela porque ainda está presente em nossos hábitos, e queremo-la de volta porque ainda está em nossos hábitos.

Para dar uma ideia ligeira (mais do que isso não seria possível aqui) sobre como tudo isso funciona, preciso fazer três coisas: (1) explicar no que consistia a estrutura filológica do conhecimento, a despeito de suas diversas áreas e temas; (2) exemplificar algumas das práticas fundamentadas naquela estrutura com a qual ainda estamos fortemente comprometidos; (3) exemplificar como essas práticas são questionadas de uma perspectiva "pós-traça".

Faço isso do seguinte modo. Chamo atenção a certos nós de convergência para compreender a consistência da filologia como uma estrutura de conhecimento. Esses nós são pontos de encontro para várias dimensões da filologia: fillologia clássica e histórica, a filologia da edição de texto e pesquisa, filologia comparativa, filologia como base da história ou crítica literária, filologia etnográfica, etc. Identificar esses nós não é o mesmo que oferecer algo tão estável e coercitivo quanto uma definição; a convergência da filologia nesses nós confere sentido à variedade e a à extensão da filologia. Esses nós em questão não são cada qual uma só coisa. Cada nó é um grupo de formulações e pressupostos subjacentes às práticas, muitas vezes em certo desacordo. Além disso, cada um desses nós é exemplificado por certas práticas de coesão, às quais em grande medida nós ainda subscrevemos. E os questionamentos sobre essas práticas, de uma perspectiva pós-traça, são dados juntamente com seus contornos. Considerando que há pouco espaço para uma elaboração - que exigiria mais volumes -, apresento os nós, as práticas exemplares e os questionamentos póstraça em termos bem gerais - e espero ter tempo para depois explorar alguns deles.

Há quatro desses nós, descritos nas quatro seguintes seções: estabelecendo o texto, origens e gênese, aspiração à unidade, e fundamentação institucional.

\section{Nó 1: Estabelecendo o Texto}

Estabelecer o texto implica torná-lo objetivamente estável e disponível, a fim de que as ambivalências e instabilidades textuais sejam capturadas e preparadas para a aplicação acadêmica, assim como reguladas para a atividade profissional. Isso envolve práticas tais como proceder à leitura cerrada, identificar edições definitivas, atribuir uma autoria estável e unitária, organizar um arquivo (ou cânone ou currículo) e policiar adequadamente os regimes de propriedade intelectual.

A necessidade da leitura cerrada é ainda firmemente advogada hoje, e isso não implica simplesmente ler atentamente conforme dado propósito ou necessidade. A leitura cerrada é tida como útil em si mesma, e entendida como o núcleo funcional da investigação literária e linguística. As formulações conceituais mais gerais na literatura e na linguagem são muitas vezes baseadas na 
leitura cerrada de um ou dois textos selecionados. Metaforicamente, para ser capaz de olhar para um texto de modo próximo, como sob um microscópio, e mapear ou determinar suas características instáveis, precisa-se fixá-lo, "cerrá-lo", da mesma forma como uma amostra microscópica é posicionada sobre a lâmina. A base para estabelecer o texto através da leitura cerrada seria, então, análoga ao posicionamento do texto na lâmina, como se desse modo o texto se mantivesse estável, aguçando o foco analítico sobre suas ambivalências e instabilidades.

A relevância da leitura cerrada é hoje tão firmemente enraizada na academia que raramente se lhe questiona ou põe em perspectiva. Questionamentos ocasionais tipicamente surgiram junto a considerações sobre a pragmática material da leitura. A proposta de uma "leitura distanciada", nas "Conjectures on World Literature" (2002), de Franco Moretti, foi oferecida timidamente como um modo de perspectivar os limites da leitura cerrada. A ideia era a de que a leitura cerrada somente seria possível com um "pequeno cânone", ao passo que uma área tão ampla quanto a literatura mundial demanda uma abordagem mais larga. "Leitura distanciada" poderia ser essa abordagem expansiva, consistindo numa síntese de leituras cerradas que existem já depois de aceites e sem um retorno aos textos primários. A base da leitura cerrada, então, não foi aberta ao debate; foi aceita e depois reconstruída na leitura distanciada. Um mais propositivo desafio para a leitura cerrada apareceu em Distant Reading (2005), de Peter Middleton, que compreendeu a distância como implícita na natureza contingente da leitura em meio à densidade de preocupações do cotidiano. Vista dessa perspectiva, a fixação do texto proposta na leitura cerrada é um paradoxo: "uma leitura cerrada específica de um poema é quase sempre percebida como aproximação de uma leitura ideal de um poema, embora ao mesmo tempo tal ideal seja tacitamente admitido como irrealizável" (2005, p. 9). A aspiração a uma leitura ideal deriva da presunção de estabelecer o texto; a princípio, se ele pode ser presumivelmente estabelecido, ele decerto pode ser completamente compreendido. Middleton argumentou que a questão da leitura em meio ao cotidiano demanda mais atenção conceitual. Esse tipo de leitura distante, em meio ao cotidiano, em meio às múltiplas preocupações, pode ser pensado como o outro da leitura cerrada - como leitura casual. Sem dúvida, as práticas de leitura cerrada, especialmente no quadro institucional, não podem ser colocadas em perspectiva sem que se perceba o caráter ubíquo e pouco visível da leitura casual em meio à generalidade das circunstâncias de recepção. E, presumidamente, é raro que textos literários se tornem objetos de atenção acadêmica, às leituras cerradas apropriadas, sem o rito de passagem da leitura casual. É possível apreender toda a estrutura da cultura impressa (sua história e regimes correntes) como baseados na leitura casual, escassamente nomeada em fóruns acadêmicos e tratada com desprezo. O desprezo é provavelmente expressão de um resquício de medo filológico quanto à incapacidade de estabelecer o texto, a ansiedade da fluidez textual.

Vários modos de estabelecer edições de texto "definitivas", "estandardizadas", "autorais", "finais" são efetivamente projetados para estabelecer o texto e derivam da empresa filológica de edição textual - além de 
continuar tendo circulação. Os modos correntes de fixar os textos são extrapolações da metodologia filológica, baseando-se em métodos desenvolvidos para, por exemplo, recuperar textos definitivos ou "autorais" a partir de variantes, versões fragmentárias, ou para embasar uma formação ideológica institucional existente. A modificação de tais métodos a fim de que sirvam aos circuitos da contemporânea produção e recepção de textos (nas culturas impressas e depois nas culturas audiovisuais e digitais) é efetivamente também a conservação das práticas filológicas. Tais práticas de estabelecer ou fixar textos, como aquela da leitura cerrada, parecem ter validade própria e simplesmente funcionar entre os regimes acadêmico, editorial e da propriedade intelectual. De modo semelhante, na história da cultura impressa - em que o códice replicável é a forma material dominante dos textos -, a centralidade do autor como chave para estabelecer textos é parte e parcela da metodologia filológica. A autoridade da autoria (o peso conferido à intenção autoral) na determinação do que é uma edição "definitiva", "estandardizada", "autoral", "final", está tão profundamente arraigada nos regimes acadêmico, editorial e legal que parece estar para além de qualquer questionamento - mesmo em meio a dúvidas sobre o conceito de autoria.

Posteriormente mencionarei alguns dos modos nos quais a pragmática materialista da produção, circulação e recepção perturba esses preceitos de autoria e edição definitiva. Apenas quis aqui assinalar essa ideia, mas ela é mais pertinente para outros nós.

\section{Nó 2: Origens e Gênese}

Diferentes áreas da investigação filológica parecem ter com frequência convergido em noções preconcebidas de origens e gênese. De modo breve, a noção de origem tem a ver com determinar a fonte de que derivou um determinado objeto (um texto específico, característica sintática, artefato cultural, etc.), enquanto gênese trata do processo envolvido nessa derivação. Dependendo de como o objeto sob exame é estabelecido (p. ex., um texto em particular), determinam-se sua origem específica e imediata (p. ex., um autor) e gênese (p. ex., respeitante a influências maleáveis, circunstâncias sociais). Mas a derivação de qualquer objeto dado geralmente envolve um conjunto de fontes tangenciais e menos imediatas, as quais por sua vez são objetos que derivam de outras fontes, e assim por diante. $\mathrm{O}$ objetivo último é trabalhar no sentido contrário (perseguindo a gênese) de modo a projetar um ponto absoluto de origem (p. ex., que seria um Ur-texto, originário, linguagem ancestral, cultura primeva ou nacionalidade essencial). Assume-se então que os traços de origem e gênese estão disponíveis no presente - seja para um objeto (como um texto ou expressão linguística particular) ou para uma formação maior (uma linguagem, forma cultural, gênero) -, e os princípios racionais para trabalhar os traços no presente através do processo gerativo até o ponto de origem constituem a metodologia filológica. Essa metodologia assume que uma unidade originária sustenta diferentes 
particularidades, e que todas as particularidades estão ligadas. O foco em particularidades e processos permite que relações sintagmáticas sejam estabelecidas - como entre particulares nações e culturas, particulares linguagens, particulares tradições literárias, particulares autores, particulares textos (círculos hermenêuticos). Essa abordagem filológica também tende a atribuir valor normativo positivo para fontes originais e processos gerativos, de modo que origens e gênese exercem sobre o presente uma força normativa: por exemplo, ao ser exemplar, ao prover definições, ao sugerir princípios regulativos éticos ou políticos ou acadêmicos, ao apresentar formas "puras" antes de "contaminações" ou "corrupções", ao permitir a justificação de uma presente hierarquia. A atitude de veneração (da grandeza, da tradição, do clássico) que é associada à filologia surge desse pendor de atribuir força normativa positiva às origens e gêneses.

A centralidade atribuída ao autor como o criador e progenitor dos textos foi questionada de modo sustentado e persistente, bem como os regimes de propriedade intelectual e pedagógico que aí se pautam. A declaração de Roland Barthes da "morte do autor" (1968) efetivamente reconceitualizou os textos como espaços de escrita, asseverando a centralidade de processos (escrita e leitura) que não podem ser fixados a produtos acabados ou agentes definitivos. A descrição de Foucault da "função autor" (numa lição de 1969) focou também a escrita, mas sobretudo notou que a construção do autor como criador e progenitor tem uma história relativamente recente, pautada por uma ideologia de controle. De uma direção distinta, no curso dos anos 1970 e 1970, especialmente através do debate entre Wolfang Iser, Hans Jauss e Stanley Fish, a teoria da recepção e a crítica da resposta do leitor provocaram uma espécie de dispersão da figura do autor como criador. Leitores empíricos foram então examinados de maneira variada (HOLLAND, 1975; BLEICH, 1978; STEIG, 1989; MIALL, 2006) sem problematizar os pressupostos relativos a autores. Desafios mais produtivos ao conceito filológico de autor apareceram de outras direções, particularmente através de encontros com regimes de propriedade intelectual e com o desenvolvimento de tecnologias textuais (de WOODMANSEE e JASZI, 1994, a ZEMER, 2007). Um abrangente argumento traça o enrijecimento das definições e prerrogativas do autor em regimes de propriedade intelectual desde o século XVIII, quando o autor era reputado como o possuidor definitivo dos textos (na medida em que textos são vistos como "originais") em detrimento de vários outros agentes (inclusive leitores) que acionam o texto. Recentemente, as mudanças das formas materiais do texto, do impresso (o códice) aos media digitais com aparatos hipertextuais e de rede social, solicitaram a reconsideração não apenas da materialidade textual como do acabamento textual e das versões definitivas, do autor como criador e genitor, das práticas de arquivo, da propriedade intelectual e da originalidade, e das próprias noções de textualidade e literariedade. Formulações persuasivas que debilitam os acordos convencionais nessas áreas apareceram, como: leitura e escrita interativa ou participativa (BOLTER, 1991; GAGGI, 1997); práticas de arquivo e edição compatíveis com uma "textualidade fluida" (Bryant, 2002) e "leitura deformativa" (MCGANN; SAMUELS, 1999; MCGANN, 2001); novas formas de literariedade na "literatura 
ergódica" (AARSETH, 1997) ou na "literatura eletrônica" (HAYLES, 2007; 2008).

As relações sintagmáticas que se estabelecem através da busca por origens na linguagem e textos com origens nas culturas e nações (compreendidas como coletivos com ancestralidade comum, não raro confundidas com raça ou etnicidade) foram submetidas a um rico corpo de estudos críticos que eu não precisaria sequer sumarizar. É inquestionável que o enorme investimento da filologia comparativa na conceitualização da nacionalidade e também o investimento dos estados políticos na filologia comparativa para consolidar solidariedades nacionais significam que os princípios de origens e gênese ainda estão profundamente implicados nas instituições do Estado. Há algo "grudento" na ideia de nação (com esse irrevogável eco de nasci, naissance, natal em seu interior), especialmente nos estudos literários e da linguagem; a noção de uma profunda (quase geneticamente inscrito) pertença nacional continua a ter um apelo retórico e nomenclatório que é evocado a cada vez que, sem pensar, dizemos "literatura brasileira" ou "literatura britânica" e assim por diante. Em termos críticos, sabemos o que há de impróprio em tais construções da integridade nacional e cultural; elas parecem, porém, estar irrevogavelmente implicadas na prática institucional e na própria linguagem habitual da crítica.

\section{Nó 3: Aspiração à Unidade}

Unidade e universalidade não são limítrofes. A asserção universalmente relevante não precisa ser uma que visa unificar diferentes perspectivas num esquema abrangente: por exemplo, a impossibilidade de um esquema abrangente bem pode ser uma proposição universalmente relevante. Contudo, uma aspiração à unidade de fato envolve buscar ou construir um esquema abrangente que reúna perspectivas diversas em eixos comuns de compreensão e explicação e, dessa feita, apresente um tipo particular de reivindicação de universalidade. Diferentes aspectos da filologia convergem numa aspiração à unidade em relação aos seus foci imediatos (p. ex., uma compreensão unificada de um autor, de uma nação ou cultura particular, da integridade de textos particulares), e daí a mais amplos âmbitos (p. ex., a unidade de princípios linguísticos, a unidade em métodos de crítica textual, a unidade na conceitualização da cultura em geral), e daí a um horizonte de totalidade ou completude (p. ex., o mundo mesmo, a humanidade mesma). A reivindicação filológica de uma relevância universal segue dessa aspiração à unidade.

O material nuclear da filologia - linguagens e textos - resiste a esquemas unificantes que sejam demonstrável, objetiva e anistoricamente válidos. Além disso, vários métodos filológicos orientam-se precisamente na direção de cuidar dos textos de modo a alcançar uma compreensão profunda dessa resistência: fixar textos através da leitura cerrada, através da proximidade ao grão da linguagem, proximidade à forma material dos textos, e assim por diante - uma fixação 
microscópica que abre a possibilidade do que Sean Gurd chama de "vertiginosa contingência" do texto: "ver os pontos em que as juntas não se encaixam, onde as palavras e linhas parecem estranhas ou fora de contexto [...] textos começam a parecer arranjos de fragmentos mal ajustados ou tradições de variância que nunca poderiam ser ajuntadas numa única forma "perfeita" (2010, p. 11). Além disso, de formas bastante restritas, mas significativas, continuam aparecendo nos círculos acadêmicos convenções familiares que são remanescentes de aspirações filológicas à unidade mesmo onde a filologia não é defendida - com efeito, até afastada e silenciada. De forma restrita, por exemplo, a atitude da investigação literária que fetichiza a integridade do texto - sustentando que um texto deve ser considerado e compreendido não apenas de modo próximo [closely] mas como um todo consistente ou uma estrutura unificada - é um passo nesse sentido. Assim, na prática crítica textos ainda são habitualmente "interpretados" como consistentes ao invés de inconsistentes, congruentes ao invés de incongruentes, reconciliados ao invés de contraditórios, estáveis ao invés de fluidos. Claro, a crítica desconstrucionista e a pós-moderna desbastaram, de maneira estudada, tais suposições habituais; o afastamento da linguística em relação à filologia teve a ver com o desenvolvimento métodos de corpus que debilitaram intensamente a noção da completude do texto; e, de fato, a própria prática acadêmica também habitual constantemente reparte o texto em citações selecionadas, sumário e arranjo das partes.

Investimentos filológicos em apreender a unidade do humano universal e a base universal da história e da cultura, em última instância, foram realizados em sua maior parte ao longo do século XVIII e início do século XIX na Europa Continental. Isso envolveu a extrapolação de princípios filológicos gerais, a partir de práticas de longa data da filologia clássica, da codicologia, da fílologia histórica, da edótica, e assim por diante, e também a clarificação da relação complementar da filologia à filosofia ou como concomitante à hermenêutica. Os argumentos que permitiram a aspiração ser concebida e expressa podem ser utilmente traçados através da Scienza Nuova (1725) de Giambattista Vico e da obra de Friedrich Schleiermacher (especialmente Hermeneutik und Kritik, 1838). Isto, no entanto, não é do escopo dessa comunicação. É suficiente dizer que tais conceitos, que por vezes ainda parecem ser a substância da racionalidade crítica, têm provavelmente suas premissas em poderosos artigos de fé - especialmente, no fundo, fé numa compreensão monoteística do mundo sociocultural. De modo singelo, eu até poderia dizer que artigos de fé politeístas e, especialmente, a indiferença ateia à fé põem essa convicção na unidade numa perspectiva mais provisional.

\section{Nó 4: Fundamentação institucional}

A filologia foi definitivamente realizada em formas institucionais. Dessa maneira, a filologia está implicada em e materializada através de atos 
institucionais de ensino e investigação; formulações filológicas proveem a raison d'être da moderna universidade e sustentam as políticas educacionais; e a filologia também está associada a processos de profissionalização e especialização. No entanto, a fundamentação institucional da filologia, a economia política e estruturas de poder que mantêm a filologia à tona podem ser vistos como exteriores à filologia: métodos, conceitos, formulações e aspirações filológicas parecem ser de tal modo elaborados para não localizar a filologia como subordinada a prerrogativas institucionais e suas dispensações políticoeconômicas e ideológicas. A filologia é em geral formulada ou como microprática (lidar com textos) ou como macroaspiração (compreensão duma totalidade) ou, principalmente, como a relação entre essas duas dimensões. Pensa-se na filologia ou relativamente ao esforço individual (uma autoimagem), ou como projeto cultural/nacional geneticamente fundado, ou como uma visão holística emergindo do estudo cuidado, ou todos esses em conjunto.

$\mathrm{O}$ não engajamento da filologia com sua própria fundamentação institucional, enquanto aparecendo de qualquer modo como uma forma de investigação institucional, tem sido e continua sendo uma posição útil. Dá à filologia resiliência e faz-lhe receptiva e aberta à assimilação. As práticas e preconcepções filológicas podem ser implicadas na vida institucional habitual e rotineira sem serem ostentórias, mas com efeito de um modo tácito e quieto. Essas práticas e preconcepções podem conferir validadade num micro e num macroâmbito a qualquer ordem ideológica e organização estabelecida que subsidie seus inquéritos, ao existir no interior daquela ordem sem interrogá-la (constantemente negando aportes ideológicos) e ao dar àquela ordem um quinhão na prática especializada e nas ambições universalistas/unificantes. Práticas e pressupostos filológicos explícita ou implicitamente trabalharam com dispensações e regimes monárquicos, autocráticos, teocráticos, fascistas, comunistas e liberaldemocráticos sem serem completamente afixados a nenhum deles. $\mathrm{O}$ fato de que as intuições (contingentes e limitadas mas não injustificadas) da consanguinidade da filologia com o ultranacionalismo e o racismo não obliteraram a aquisição da filologia nem mesmo entre os regimes e instituições que ostensivamente os abominam é evidência de sua elasticidade.

Ou seja, focar na economia política e nas estruturas de poder que governam os estudos literários e linguísticos é pôr, de imediato, a estrutura filológica do conhecimento - ajuntada em torno dos três nós de que tratamos sob uma luz interrogativa.

Onde nós ficamos, então, com tudo isso? $\mathrm{Na}$ - espero - ambígua conjuntura do presente, em que a herança das práticas filológicas em meio ao anacronismo da estrutura filológica do conhecimento constantemente se move contra a perspectiva pós-traça da pesquisa literária e linguística. $\mathrm{O}$ caminho à 
frente poderia consistir em operar cuidadosamente através das nossas crenças e razões como pesquisadores para atingir uma prática pós-filológica e pós-traça reciprocamente determinante.

\section{REFERÊNCIAS BIBLIOGRÁFICAS}

AARSETH, Espen J. Cybertext: Perspectives on Ergodic Literature. Baltimore, MD: Johns Hopkins University Press, 1997.

ASSIS, Joachim Maria Machado de. Dom Casmurro. Traduzido por John Gledson. Oxford: Oxford University Press, 1997.

AUERBACH, Erich. Mimesis: The Representation of Reality in Western Literature. Traduzido por Willard Trask. Princeton: Princeton University Press, 1953 [1946].

Philology and Weltliteratur. Traduzido por Maire Said e Edward Said. Centennial Review, v. 1, n. 13, p. 1-17, 1969.

BAJOHR, Hannes et al. (Orgs.). The Future of Philology. Newcastle upon Tyne: Cambridge Scholars, 2014.

BALDICK, Chris. The Social Mission of English Criticism, 1848-1932. Oxford: Clarendon, 1983.

BELSEY, Catherine. Critical Practice. London: Methuen, 1980.

BLEICH, David. Subjective Criticism. Baltimore: Johns Hopkins University Press, 1978.

BOLTER, Jay David. Writing Space: The Computer, Hypertext, and the History of Writing. Hillsdale NJ: L. Erlbaum 1991.

BRYANT, John. The Fluid Text: A Theory of Revision and Editing for Book and Screen. Ann Arbor: The University of Michigan Press, 2002.

COURT, Franklin E. Institutionalizing English Literature: The Culture and Politics of Literary Study, 1750-1900. Stanford Cal.: Stanford University Press, 1992.

CRAWFORD, Robert. Devolving English Literature. Oxford: Clarendon, 1992.

DE MAN, Paul. The Resistance to Theory. Minneapolis: University of Minnesota Press, 1986.

DIXON, John. A Schooling in 'English': Critical Episodes in the Struggle to Shape Literary and Cultural Studies. Buckingham: Open University Press, 1991. 
DOYLE, Brian. English and Englishness. London: Routledge, 1989.

EAGLETON, Terry. Literary Theory: An Introduction. Oxford: Blackwell, 1983.

GAGGI, Silvio. From Text to Hypertext: Decentring the Subject in Fiction, Film, the Visual Arts. Philadelphia: University of Pennsylvania Press, 1997.

GRAFF, Gerald. Professing Literature: An Institutional History. Chicago: University of Chicago Press, 1987.

GUMBRECHT, Hans Ulrich. The Powers of Philology: Dynamics of Textual Scholarship. Champaign IL: University of Illinois Press, 2002.

GURD, Sean (Org.). Philology and Its Histories. Columbus: Ohio State University Press, 2010.

HARPHAM, Geoffrey Galt. The Humanities and the Dream of America. Chicago: University of Chicago Press, 2011.

HAYLES, N. Katherine. Electronic Literature: What is it?. Eliterature, v. 0, n. 1.

Electronic Literature: New Horizons for the Literary. Notre Dame, IN: University of Notre Dame Press, 2008.

HOLLAND, Norman. Five Readers Reading. New Haven: Yale University Press, 1975.

JESPERSEN, Otto. Language: Its Nature, Development and Origin. London: George Allen \& Unwin, 1922.

LERER, Seth. Error and the Academic Self: The Scholarly Imagination, Medieval to Modern. New York: Columbia University Press, 2002.

MCGANN, Jerome. Radiant Textuality: Literature After the World Wide Web. Basingstoke: Palgrave, 2001.

MCGANN, Jerome; SAMUELS, Lisa. "Deformance and Interpretation". New Literary History, v. 1, n. 30, p. 25-56.

MIALL, David S. Literary Reading: Empirical and Theoretical Studies. New York: Peter Lang, 2006.

MIDDLETON, Peter. Distant Reading: Performance, Readership, and Consumption in Contemporary Poetry. Tuscaloosa: University of Alabama Press, 2005.

MILLER, Thomas P. The Formation of College English: Rhetoric and Belles Lettres in the British Cultural Provinces. Pittsburgh: Pittsburgh University Press, 1997. 
- The Evolution of College English: Literacy Studies from the Puritans to the Postmoderns. Pittsburgh: University of Pittsburgh Press, 2010.

MOMMA, Haruko. From Philology to English Studies: Language and Culture in the Nineteenth Century. Cambridge: Cambridge University Press.

MORETTI, Franco. "Conjectures on World Literature". New Left Review, v. 1, n. 1., p. 54-68.

Newbolt Report. The Teaching of English in England: Being the Report of the Departmental Committee Appointed by the President of the Board of Education to Inquire into the Position of English in the Educational System of England. London: HM Stationary Office, 1926 [1921].

NICHOLS, Stephen G. "Introduction: Philology in a Manuscript Culture". Speculum (“The New Philology” special issue), v. 1, n. 0, p. 1-10.

"Why Material Philology". In TERVOOREN, Helmut \& WENZEL,

Horst

(Orgs.) Zeitschrift für Deutsche Philologie 116, Philologie als Textwissenschaft: Alte und Neue Horizonte. Berlin-Tiergarten: Erich Schmidt Verlag, 1997.

OHMANN, Richard. English in America: A Radical View of the Profession. New York: Oxford University Press, 1976.

PALMER, D.J. The Rise of English Studies: An Account of the Study of English Language and Literature from its Origins to the Making of the Oxford English School. London: Oxford University Press, 1965.

POLLOCK, Sheldon. "Future Philology? Fate of a Soft Science in a Hard World". Critical Inquiry, v. 4, n. 35, p. 931-61.

SAID, Edward. Humanism and Democratic Criticism. New York: Palgrave Macmillan, 2004.

SCHLEIERMACHER, Friedrich. Hermeneutics and Criticism and Other Writings. Traduzido em: Andrew Bowie. Cambridge: Cambridge University Press, 1998 [1838].

SCHOLES, Robert. The Rise and Fall of English: Reconstructing English as a Discipline. New Haven: Yale University Press, 1998.

STEIG, Michael. Stories of Reading: Subjectivity and Literary Understanding. Baltimore: Johns Hopkins University Press, 1989.

TURNER, James. Philology: The Forgotten Origins of the Modern Humanities. Princeton: Princeton University Press, 2014. 
VICO, Giambattista. The First New Science. Traduzido por Leon Pompa. Cambridge: Cambridge University Press, 2002 [1725].

WARREN, Michelle R. "Post-Philology". IN: INGHAM, Patricia Clare e WARREN, Michelle R. (Orgs.). Postcolonial Moves: Medieval through Modern. New York: Palgrave Macmillan, 2003.

WOODMANSEE, Martha e JASZI, Peter (Orgs.). The Construction of Authorship: Textual Appropriation in Law and Literature. Durham NJ: Duke University Press, 1994.

ZEMER, Lior. The Idea of Authorship in Copyright. Aldershot: Ashgate, 2007.

ZIOKOLWSKI, Jan (Org.). On Philology. University Park: The Pennsylvania State University Press, 1990.

Recebido em 26/09/2017

Aceito em 23/12/2017 